\title{
Effect of coadministration of rifampicin on the pharmacokinetics of linezolid: clinical and animal studies
}

Satsuki Hashimoto ${ }^{1,2^{*}} \mathbb{D}$, Kyoko Honda ${ }^{1}$, Kohei Fujita' ${ }^{1}$, Yuka Miyachi $^{1}$, Kazuya Isoda' ${ }^{1}$ Ko Misaka', Yukio Suga ${ }^{3}$, Satoshi Kato ${ }^{4}$, Hiroyuki Tsuchiya ${ }^{4}$, Yukio Kato ${ }^{3}$, Masaki Okajima ${ }^{5}$, Takumi Taniguchi ${ }^{5}$, Tsutomu Shimada ${ }^{1,2}$ and Yoshimichi Sai ${ }^{1,2}$

\begin{abstract}
Background: Combination therapy of linezolid (LZD) and rifampicin (RFP) may be more effective than monotherapy for treating gram-positive bacterial infections, but several studies have suggested that RFP decreases LZD exposures, thereby increasing the risk of therapeutic failure and emergence of LZD-resistant strains. However, the mechanism of the drug-drug interaction between LZD and RFP is unknown.
\end{abstract}

Methods: We conducted a prospective, open-label, uncontrolled clinical study in Japanese patients receiving LZD and RFP to evaluate the effect of coadministered RFP on the concentration of LZD. In animal study in rats, the influence of coadministered RFP on the pharmacokinetics of LZD administered intravenously or orally was examined. Intestinal permeability was investigated with an Ussing chamber to assess whether coadministered RFP alters the absorption process of LZD in the intestine.

Results: Our clinical study indicated that multiple doses of RFP reduced the dose-normalized trough concentration of LZD at the first assessment day by an average of $65 \%$. In an animal study, we found that multiple doses of RFP significantly decreased the area under the concentration-time curve, the maximum concentration and the bioavailability of orally administered LZD by $48 \%, 54 \%$ and $48 \%$, respectively. In contrast, the pharmacokinetics of intravenously administered LZD was unaffected by the RFP pretreatment. However, investigation of the intestinal permeability of $L Z D$ revealed no difference in absorptive or secretory transport of $L Z D$ in the upper, middle and lower intestinal tissues between RFP-pretreated and control rats, even though RFP induced gene expression of multidrug resistance protein $1 \mathrm{a}$ and multidrug resistance-associated protein 2.

Conclusions: Therapeutic drug monitoring may be important for avoiding subtherapeutic levels of LZD in the combination therapy. The drug-drug interaction between LZD and RFP may occur only after oral administration of LZD, but is not due to any change of intestinal permeability of LZD.

Trial registration: UMIN, UMIN000004322. Registered 4 October 2010.

Keywords: Linezolid, Rifampicin, Drug-drug interaction, Therapeutic drug monitoring, Pharmacokinetics, Adverse event

\footnotetext{
* Correspondence: satsuki-0509@staff.kanazawa-u.ac.jp

'Department of Hospital Pharmacy, University Hospital, Kanazawa University,

13-1, Takara-machi, Kanazawa, Ishikawa 920-8641, Japan

${ }^{2}$ Department of Medicinal Informatics, Graduate School of Medical Sciences,

Kanazawa University, 13-1, Takara-machi, Kanazawa, Ishikawa 920-8641, Japan

Full list of author information is available at the end of the article
}

(c) The Author(s). 2018 Open Access This article is distributed under the terms of the Creative Commons Attribution 4.0 International License (http://creativecommons.org/licenses/by/4.0/), which permits unrestricted use, distribution, and reproduction in any medium, provided you give appropriate credit to the original author(s) and the source, provide a link to the Creative Commons license, and indicate if changes were made. The Creative Commons Public Domain Dedication waiver (http://creativecommons.org/publicdomain/zero/1.0/) applies to the data made available in this article, unless otherwise stated. 


\section{Background}

Linezolid (LZD) is an oxazolidinone antimicrobial agent with broad-spectrum activity against gram-positive bacteria, including methicillin-resistant Staphylococcus aureus (MRSA) and vancomycin-resistant Enterococcus faecium [1]. It is rapidly absorbed after oral administration, with $100 \%$ bioavailability (F), and is metabolized by nonenzymatic oxidation into two inactive metabolites, without the involvement of any major cytochrome P450 (CYP) [2-4]. About $30 \%$ of LZD is eliminated in unchanged form in the urine, and the major metabolites are also mainly excreted via the kidney [4]. On the other hand, the mechanisms involved in the permeability of LZD in small intestines have not been fully clarified.

Early studies suggested that therapeutic drug monitoring (TDM) and dose adjustment based on body weight might be unnecessary during LZD therapy. However, some recent studies have indicated that major adverse events associated with LZD, particularly thrombocytopenia and anemia, could appear dose-dependently [5-9]. Moreover, there are several reports of drug-drug interactions (DDI) with LZD in humans: coadministration of omeprazole, amiodarone, amlodipine, sertraline or clarithromycin with LZD increased the exposure to LZD [9-11]. It was speculated that P-glycoprotein (P-gp) could be involved in these DDIs, because omeprazole, amiodarone, amlodipine, sertraline or clarithromycin are known to be P-gp inhibitors. On the other hand, it has been reported that rifampicin (RFP) decreases LZD exposure in terms of trough concentration $\left(\mathrm{C}_{\text {min }}\right)$, maximum concentration $\left(\mathrm{C}_{\max }\right)$ and area under the concentration-time curve (AUC), and RFP also reduced the incidence of LZD-induced thrombocytopenia and/or anemia [12-15]. The mechanism of the DDI between LZD and RFP remains unknown. The various DDIs with LZD may result in marked inter-individual variability in LZD exposure and concentration-dependent adverse events. Thus, it seems necessary to monitor LZD concentration during administration, and also to identify the mechanisms involved in these DDIs.

The aim of the present study was: (i) to evaluate the effect of coadministered RFP on the concentration of LZD in a prospective, open-label, uncontrolled clinical study, (ii) to determine the influence of coadministered RFP on the pharmacokinetics of LZD administered intravenously or orally in rats, and (iii) to assess whether coadministered RFP alters the absorption process of LZD in the intestine.

\section{Methods}

\section{Materials}

LZD injection solution (Zyvox Injection, $600 \mathrm{mg}$ ) used for intravenous administration and tablets (Zyvox Tablets, $600 \mathrm{mg}$ ) used for oral administration in rats were purchased from Pfizer Japan, Inc. (Tokyo, Japan). RFP, Lucifer yellow (LY) and rhodamine 123 (Rho123) were purchased from Sigma-Aldrich (Tokyo, Japan). Pentobarbital and diethyl ether were purchased from Nakalai Tesque, Inc. (Kyoto, Japan). All other chemicals used were of analytical or high performance liquid chromatography (HPLC) grade.

\section{Subjects and study design}

This prospective, open-label, uncontrolled study was conducted from October 2010 through October 2013 at Kanazawa University Hospital. The study was approved (UMIN000004322) by the ethics committee of Kanazawa University Hospital, and written informed consent was obtained from all participants, who were adults ( $\geq 20$ years) being treated with oral LZD $600 \mathrm{mg}$ every $12 \mathrm{~h}$. Patients who were treated with RFP after the initiation of LZD therapy were excluded from the study. The main reasons for LZD treatment were orthopedic device-related infections, and bone and joint infections. Microbiological isolates were identified in $90 \%$ of cases, and were mainly MRSA and Staphylococcus epidermidis. None of the isolates was resistant to LZD according to the Clinical and Laboratory Standards Institute criteria, and all of the isolates had an MIC $\leq 2 \mu \mathrm{g} / \mathrm{mL}$.

Patients were divided into two subgroups. One (the LZD/RFP group) received oral coadministration of RFP $450 \mathrm{mg}$ every $24 \mathrm{~h}$ for 3-15 days, while the other (the LZD group) did not receive RFP coadministration. At the first assessment day (on days 2-5 after the initial administration), blood was sampled just before the subsequent administration of LZD to measure the trough concentration. The blood was centrifuged, and the serum was stored at $-30{ }^{\circ} \mathrm{C}$ until analysis.

Thrombocytopenia was defined as a decrease in the platelet count to $<130,000 / \mu \mathrm{L}$, and anemia was defined as a decrease in the hemoglobin $(\mathrm{Hb})$ concentration to $<8 \mathrm{~g} / \mathrm{dL}$. We determined fourteen variables: sex, age, body weight, estimated glomerular filtration rate (eGFR), $\mathrm{C}$-reactive protein (CRP), platelet count, $\mathrm{Hb}$ concentration, duration of LZD therapy, total dosage, daily dose, trough concentration of LZD at the first assessment day during LZD therapy, number of instances of TDM, concomitant drugs received during LZD therapy, and success rate. Dose adjustment of LZD was performed to avoid LZD-related adverse events. eGFR was estimated based on the Clinical Practice Guidebook for Diagnosis and Treatment of Chronic Kidney Disease.

After an average follow-up of 2.4 years, patients were considered cured if there was no clinical, biological or radiological evidence of infection. In other cases, treatment was considered to have failed.

\section{Animal experiments}

Male Sprague-Dawley rats (10 weeks old) were purchased from Japan SLC, Inc. (Hamamatsu, Japan). Rats 
were housed under a 12-h light, 12-h dark cycle and were fed normal diet and water ad libitum. Rats were acclimated for 1 week before drug administration. In the RFP pretreatment study, RFP dissolved in $1 \%(\mathrm{w} /$ v) $\mathrm{CMC}-\mathrm{Na}$ was administered orally once a day at $10 \mathrm{mg} / \mathrm{kg}$ for 4 days [16]. Control rats received 1\% (w/v) $\mathrm{CMC}-\mathrm{Na}$ orally. Following these treatments, rats were given a single dose of LZD orally $(62.5 \mathrm{mg} / \mathrm{kg})$ via a gastric tube or intravenously $(45.7 \mathrm{mg} / \mathrm{kg}$ ) from the jugular vein at $12 \mathrm{~h}$ after the last RFP administration, under anesthesia with diethyl ether. Blood samples $(250 \mu \mathrm{L}$ each) were collected prior to dosing of LZD and at 0.25 , $0.5,0.75,1,2,3,6$ and $12 \mathrm{~h}$ after dosing from the opposite jugular vein, and were centrifuged to obtain plasma. All animal procedures were carried out in accordance with the Guidelines for the Care and Use of Laboratory Animals at Kanazawa University.

\section{Measurement of LZD by LC/MS}

LZD was quantitated by means of validated liquid chromatography-mass spectrometry (LC/MS) according to the procedure of Slatter et al., with minor modifications [4]. In brief, plasma samples $(100 \mu \mathrm{L})$ were mixed with acetonitrile $(100 \mu \mathrm{L})$ for $10 \mathrm{~min}$ in a shaker and then centrifuged at $10,000 \times \mathrm{g}$ for $5 \mathrm{~min}$ at $4{ }^{\circ} \mathrm{C}$. An aliquot of the supernatant $(20 \mu \mathrm{L})$ was analyzed to determine the LZD concentration. Separation was done on a Symmetry C8 column (250 × $4.6 \mathrm{~mm}, 5 \mu \mathrm{m}$; Waters, Co., Tokyo, Japan) using an isocratic mobile phase of $100 \mathrm{mM}$ ammonium acetate $(\mathrm{pH} 4.8) /$ acetonitrile $(75: 25, \mathrm{v} / \mathrm{v})$ at a flow rate of $1.0 \mathrm{~mL} /$ $\mathrm{min}$. The calibration plot was linear over the range of 0.5 to $50 \mu \mathrm{g} / \mathrm{mL}$ with a correlation coefficient $\geq 0.99$. The intraand inter-assay coefficients of variation were all $<10 \%$. The lower limit of detection was $0.5 \mu \mathrm{g} / \mathrm{mL}$. Pharmacokinetic parameters were estimated by model-independent moment analysis, including AUC, $\mathrm{C}_{\max }$, elimination rate constant $\left(\mathrm{k}_{\mathrm{e}}\right)$, half-life $\left(\mathrm{t}_{1 / 2}\right)$, total clearance $\left(\mathrm{CL}_{\mathrm{tot}}\right)$, volume of distribution $\left(\mathrm{V}_{\mathrm{d}}\right)$ and $\mathrm{F}$.

\section{RNA extraction and real-time PCR}

After euthanasia, the entire length of the rat small intestine was quickly removed. Intestinal segments were isolated and each site was defined as described below [17]. A $5 \mathrm{~cm}$ portion of the top of the small intestine was regarded as the duodenum (the upper intestine). The ileum (the lower intestine) was obtained from the final $5 \mathrm{~cm}$ portion of the intestine. The jejunum (the middle intestine) was obtained from the remaining portion. Each intestinal segment was snap-frozen in liquid nitrogen and stored at $-80{ }^{\circ} \mathrm{C}$ until analysis. Total RNA was extracted using a GenElute ${ }^{\mathrm{TM}}$ Mammalian Total RNA Miniprep Kit (Sigma-Aldrich, Tokyo, Japan), according to the manufacturer's protocol. The concentration of total RNA was measured with a NanoDrop ${ }^{\circ}$ ND-1000 spectrophotometer (NanoDrop Products, Wilmington, DE, USA). cDNA was synthesized with $2 \mu \mathrm{g}$ of total RNA using a High Capacity cDNA Reverse Transcription $\mathrm{Kit}^{\oplus}$ (Applied Biosystems, Foster city, CA, USA), according to the manufacturer's instructions. To prepare a standard curve, cDNA was mixed with Platinum ${ }^{\circ}$ PCR SuperMix (Invitrogen Life Technologies Japan Ltd., Tokyo, Japan), and amplified by using a Gene Amp ${ }^{\circ}$ PCR System 9700 (Applied Biosystems, Foster city, CA, USA). The PCR conditions were 35 cycles at $94{ }^{\circ} \mathrm{C}$ for $15 \mathrm{~s}, 60{ }^{\circ} \mathrm{C}$ for $15 \mathrm{~s}$ and $72{ }^{\circ} \mathrm{C}$ for $30 \mathrm{~s}$. PCR products were separated on a $2 \%$ agarose gel. For gene expression studies, the cDNA was mixed with THUNDERBIRD ${ }^{\circ}$ SYBR $^{\circ}$ qPCR Mix (Toyobo Co., Ltd., Osaka, Japan) and gene-specific primers (Invitrogen Life Technologies Japan Ltd., Tokyo, Japan). The primers used were as follows: multidrug resistance protein 1a (Mdr1a/Abcb1a), 5'-T GAACTGTGACCATGCGAGATGTTAAATA-3' and 5'GTCTCTGAAGACTCTAAAATGGACTAAATG-3' for a 153-bp fragment; multidrug resistance-associated protein 2 (Mrp2/Abcc2), 5'-TTCACGGGCACATCACCA-3' and 5'-ATTCGGACCCAAACAGGATG-3' for a 102-bp fragment; breast cancer resistance protein (Bcrp/Abcg2), 5'-GTTTGGACTAAGCACAGCA-3' and 5'-TGAGTTT CCCAGAAGCCAGT-3' for a 150-bp fragment; and $\beta$-actin, 5'-TGAGCGCAAGTACTCTGTGTGGAT-3' and 5'TAGAAGCATTTGCGGTGCACGATG-3' for a 129-bp fragment. The PCR conditions for the Mx $3000 \mathrm{P}^{\circ}$ Real-Time QPCR System 9700 (Agilent Technologies, Inc., Santa Clara, CA, USA) were 40 cycles at $95{ }^{\circ} \mathrm{C}$ for $30 \mathrm{~s}$ and $60{ }^{\circ} \mathrm{C}$ for $60 \mathrm{~s}$.

\section{Measurement of intestinal permeability in an Ussing chamber}

Intestinal permeability study was examined by means of the Ussing chamber technique, as described in the literature [18]. Rho123, inulin, LZD and LY were dissolved at concentrations of $5 \mu \mathrm{M}, 5 \mathrm{mg} / \mathrm{mL}, 20 \mu \mathrm{g} / \mathrm{mL}$ and $5 \mu \mathrm{M}$, respectively, in buffer solution ( $\mathrm{pH} 7.0)$ composed of $1.4 \mathrm{mM} \mathrm{CaCl}, 5.1 \mathrm{mM} \mathrm{KCl}, 1.3 \mathrm{mM} \mathrm{KH} \mathrm{PO}_{4}, 1.3 \mathrm{mM}$ $\mathrm{MgSO}_{4} \cdot 7 \mathrm{H}_{2} \mathrm{O}, 128 \mathrm{mM} \mathrm{NaCl}, 10 \mathrm{mM} \mathrm{NaH} \mathrm{PO}_{4} \cdot 2 \mathrm{H}_{2} \mathrm{O}$, $5 \mathrm{mM}$ D-glucose, and $21 \mathrm{mM} \mathrm{NaHCO}$. Inulin and $\mathrm{LY}$ were used as paracellular permeability markers. Rats with/without RFP pretreatment for four days as above were fasted for $24 \mathrm{~h}$, then anesthetized with sodium pentobarbital (30 $\mathrm{mg} / \mathrm{kg}$, i.p.). The upper, middle, lower intestine as defined above, were collected. Segments were cut open, the muscle layer was stripped, and the intestinal sheets were mounted in Ussing chambers (Sakuma, Tokyo, Japan) with an exposed area of $0.5 \mathrm{~cm}^{2}$. Each side of the tissue was bathed with buffer solution (2 mL) under $\mathrm{CO}_{2} / \mathrm{O}_{2}$ (5\%/95\%). The entire assembly was maintained at $37{ }^{\circ} \mathrm{C}$. During the transport studies, $0.2 \mathrm{~mL}$ aliquots were taken from the receiver side at 0 , 
$30,45,60,90,120$ and $180 \mathrm{~min}$, and immediately replaced with an equal volume of buffer solution. The amount of Rho123 in the receiver side was assayed by HPLC according to the method of Cho et al., with minor modifications [19]. Concentrations of inulin were colorimetrically determined as described in the literature [20]. Concentrations of LZD were measured as described above and LY was measured by HPLC according to the method of Lin et al. [17]. Standard calibration curves were constructed for each compound within appropriate concentration ranges. In all cases, the curves displayed excellent linearity with $r^{2}>0.99$.

Apparent permeability coefficients $\left(\mathrm{P}_{\mathrm{app}}\right)$ of Rho123, inulin, LZD, and LY in $\mathrm{cm} / \mathrm{s}$, were calculated as follows:

$$
\mathrm{P}_{\text {app }}=\mathrm{P}_{\text {amount }} /\left(\mathrm{C}_{0} \cdot \mathrm{A} \cdot \mathrm{t}\right)
$$

where $\mathrm{P}_{\text {amount }}(\mu \mathrm{mol})$ is the total amount of drug that permeated to the receiver side throughout the incubation time, $C_{0}(\mu \mathrm{mol} / \mathrm{mL})$ is the drug concentration before transport on the donor side, $\mathrm{A}\left(\mathrm{cm}^{2}\right)$ is the area of the diffusion chamber for transport, and $\mathrm{t}(\mathrm{s})$ is the experimental duration. The efflux ratio (ER) was obtained as $\left(\mathrm{P}_{\mathrm{app}}, \mathrm{s}-\mathrm{m} /\right.$ $\mathrm{P}_{\text {app }}, \mathrm{m}$-s $)$, where $\mathrm{P}_{\text {app }}$, m-s $\mathrm{is} \mathrm{P}_{\text {app }}$ of absorption (mucosal to serosal, $\mathrm{m}-\mathrm{s}$ ) and $\mathrm{P}_{\mathrm{app}}, \mathrm{s}-\mathrm{m}$ is $\mathrm{P}_{\mathrm{app}}$ of secretion (serosal to mucosal, s-m).

\section{Statistical analysis}

Values are expressed as mean \pm SD. Statistical comparisons were performed by means of an unpaired Student's $t$-test. A value of $p<0.05$ was considered to indicate statistical significance.

\section{Results}

Effects of RFP coadministration on LZD concentration, adverse events and outcomes in patients

The present study included 7 patients in the LZD group and 3 patients in the LZD/RFP group. The characteristics, LZD therapy, adverse events and outcomes of the patients are shown in Table 1. No drug known to show DDI with LZD was administered during LZD therapy [9-12].

Coadministration with RFP reduced the dose-normalized trough concentration (C/D ratio) of LZD at the first assessment day by an average of $64.7 \%$.

Table 1 Baseline characteristics and clinical outcomes of patients

\begin{tabular}{|c|c|c|c|c|}
\hline & LZD group & & LZD/RFP group & \\
\hline Gender (male/female) & $4 / 3$ & & $2 / 1$ & \\
\hline Age (year) & $60 \pm 19$ & [21-82] & $51 \pm 11$ & {$[41-62]$} \\
\hline Body weight (kg) & $66.0 \pm 17.2$ & {$[46.6-95.0]$} & $57.8 \pm 14.5$ & {$[46.0-74.0]$} \\
\hline eGFR $\left(\mathrm{mL} / \mathrm{min} / 1.73 \mathrm{~m}^{2}\right)$ & $65.2 \pm 26.3$ & [32.7-105] & $99.9 \pm 34.7$ & {$[65.6-135]$} \\
\hline Baseline CRP concentration (mg/dL) & $3.0 \pm 3.1$ & {$[0.7-8.9]$} & $1.8 \pm 0.6$ & {$[1.2-2.4]$} \\
\hline \multicolumn{5}{|l|}{ LZD dose and concentrations } \\
\hline Total dose (g) & $14.3 \pm 5.2$ & {$[7.2-21.0]$} & $28.4 \pm 9.1$ & {$[18.0-34.8]$} \\
\hline Daily dose (g/day) & $1.04 \pm 0.21$ & {$[7.29-1.20]$} & $1.20 \pm 0.0$ & \\
\hline Daily dose (mg/kg/day) & $16.7 \pm 5.7$ & {$[10.5-25.8]$} & $21.6 \pm 5.0$ & {$[16.2-26.1]$} \\
\hline Duration of LZD therapy (day) & $14 \pm 6$ & {$[6-21]$} & $24 \pm 8$ & [15-29] \\
\hline Number of TDM & 21 & & 13 & \\
\hline Trough concentration at first assessment day $(\mu \mathrm{g} / \mathrm{mL})$ & $13.3 \pm 8.4$ & {$[4.7-29.4]$} & $6.9 \pm 5.0$ & {$[2.1-12.1]$} \\
\hline C/D ratio at first assessment day $(\mu \mathrm{g} / \mathrm{mL} / \mathrm{mg} / \mathrm{kg} /$ day $)$ & $0.83 \pm 0.46$ & {$[0.32-1.34]$} & $0.29 \pm 0.17$ & {$[0.13-0.47]$} \\
\hline Patients with dosage adjustments to avoid overexposure, n (\%) & $3(42.9 \%)$ & & $0(0 \%)$ & \\
\hline CRP concentration at first assessment day (mg/dL) & $4.2 \pm 4.6$ & {$[0.3-13.8]$} & $2.0 \pm 2.0$ & {$[0.7-4.3]$} \\
\hline \multicolumn{5}{|l|}{ Hematological adverse effects } \\
\hline Baseline platelet count ( $10^{6}$ platelets $\left./ \mu \mathrm{L}\right)$ & $266 \pm 88$ & [174-445] & $325 \pm 128$ & [189-443] \\
\hline Nadir platelet count ( $10^{6}$ platelets $\left./ \mu \mathrm{L}\right)$ & $150 \pm 82$ & {$[86-320]$} & $173 \pm 113$ & {$[69-293]$} \\
\hline Thrombocytopenia, n (\%) & $4(57.1 \%)$ & & $1(33.3 \%)$ & \\
\hline Baseline $\mathrm{Hb}(\mathrm{g} / \mathrm{dL})$ & $9.6 \pm 1.8$ & {$[7.3-12.9]$} & $11.4 \pm 1.2$ & {$[10.1-12.2]$} \\
\hline Nadir $\mathrm{Hb}(\mathrm{g} / \mathrm{dL})$ & $8.9 \pm 2.2$ & [6.8-12.8] & $10.4 \pm 2.8$ & [7.1-12.1] \\
\hline Anemia, n (\%) & $3(42.9 \%)$ & & $1(33.3 \%)$ & \\
\hline \multicolumn{5}{|l|}{ Outcomes } \\
\hline Success, n (\%) & $5(71.4 \%)$ & & $3(100 \%)$ & \\
\hline
\end{tabular}


Effects of RFP pretreatment on the pharmacokinetics of LZD after intravenous and oral administration of LZD to rats

When LZD was administered intravenously to rats pretreated with RFP for four days, the RFP pretreatment had no effect on the plasma concentration-time profile or the pharmacokinetic parameters of LZD (Fig. 1a, Table 2). In contrast, when LZD was administered orally to RFP-pretreated rats, RFP significantly decreased the plasma concentration of LZD (Fig. 1b), and the AUC, $\mathrm{C}_{\max }$ and $\mathrm{F}$ of LZD were significantly reduced by approximately $48.1 \%, 53.9 \%$ and $48.1 \%$ (Table 2 ).

Effects of RFP pretreatment on mRNA expression levels of Mdr1a, Mrp2 and Bcrp in the small intestine of rats

The basal expression of Mdr1a was higher in the middle and lower regions of the intestine than in the upper region, and Mrp2 was more highly expressed in the middle region (Table 3). After four days of pretreatment with
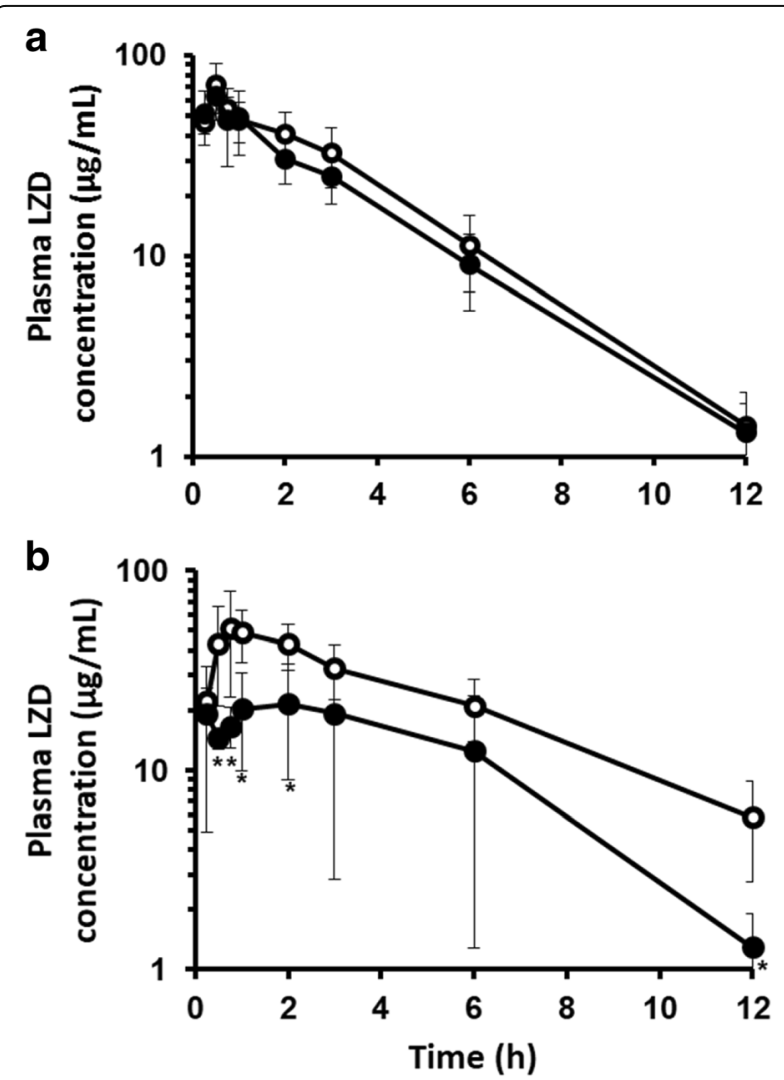

Fig. 1 Plasma concentration-time profiles of LZD after intravenous and oral administration with and without RFP. a Plasma concentrationtime profiles of LZD after intravenous administration of LZD $(45.7 \mathrm{mg} / \mathrm{kg})$ to rats with (closed circles) and without (open circles) RFP pretreatment (10 mg/kg) for four days. b Plasma concentration-time profiles of LZD after oral administration of LZD (62.5 mg/kg) to rats with (closed circles) and without (open circles) RFP pretreatment (10 mg/ $/ \mathrm{kg}$ ) for four days. Values are mean \pm SD of three to six rats. ${ }^{*} p<0.05$
Table 2 Pharmacokinetic parameters of LZD after intravenous (i.v.) and oral (p.o.) administration with and without RFP

\begin{tabular}{lllll}
\hline & & & Control & with RFP \\
\hline i.v. & $\mathrm{AUC}_{0-12}$ & $\mu \mathrm{g} / \mathrm{mL} \cdot \mathrm{h}$ & $232 \pm 61$ & $194 \pm 54$ \\
& $\mathrm{C}_{\max }$ & $\mu \mathrm{g} / \mathrm{mL}$ & $72.5 \pm 17.8$ & $65.9 \pm 15.2$ \\
& $\mathrm{k}_{\mathrm{e}}$ & $\mathrm{h}^{-1}$ & $0.292 \pm 0.041$ & $0.329 \pm 0.048$ \\
& $\mathrm{t}_{1 / 2}$ & $\mathrm{~h}$ & $2.41 \pm 0.33$ & $2.14 \pm 0.29$ \\
& $\mathrm{CL}_{\text {tot }}$ & $\mathrm{L} / \mathrm{h} / \mathrm{kg}$ & $0.210 \pm 0.064$ & $0.253 \pm 0.078$ \\
& $\mathrm{~V}_{\mathrm{d}}$ & $\mathrm{L} / \mathrm{kg}$ & $0.693 \pm 0.156$ & $0.758 \pm 0.262$ \\
p.o. & $\mathrm{AUC} \mathrm{C}_{0-12}$ & $\mu \mathrm{g} / \mathrm{mL} \cdot \mathrm{h}$ & $280 \pm 64$ & $145 \pm 103^{*}$ \\
& $\mathrm{C}_{\max }$ & $\mu \mathrm{g} / \mathrm{mL}$ & $48.0 \pm 18.1$ & $22.1 \pm 12.1^{*}$ \\
& $\mathrm{~F}$ & $\%$ & $88.3 \pm 20.1$ & $45.8 \pm 32.4^{*}$ \\
\hline
\end{tabular}

Values are mean \pm SD of three to six rats. ${ }^{*} p<0.05$

$A \cup C_{0-12}$ area under the concentration-time curve from time 0 to $12 \mathrm{~h}, C_{\max }$ maximum concentration, $k_{e}$ elimination rate constant, $t_{1 / 2}$ half-life, $C L_{\text {tot }}$ total clearance, $V_{d}$ volume of distribution, $F$ bioavailability

RFP, Mdrla mRNA was significantly increased by 1.5 -fold in the middle part of the small intestine, while Mrp2 mRNA was increased by 1.6- and 1.8-fold in the upper and middle parts of the small intestine, respectively. There was no marked change in Bcrp mRNA levels.

\section{Effects of RFP on permeability of LZD in rat small intestine (Ussing chamber technique)}

As shown in Table 4, the $\mathrm{P}_{\text {app }}$ values of inulin, a paracellular marker, in the middle intestine of control rats showed no significant difference between the absorption (mucosal to serosal, m-s; $1.40 \pm 1.27 \times 10^{-6} \mathrm{~cm} / \mathrm{s}$ ) and secretory (serosal to mucosal, $\mathrm{s}-\mathrm{m} ; 1.08 \pm 0.86 \times 10^{-}$ ${ }^{6} \mathrm{~cm} / \mathrm{s}$ ) directions, in accordance with the report by Naruhashi et al. [21]. Table 5 shows the permeability of LY, another paracellular marker, across the upper, middle and lower intestinal tissues. The values of $\mathrm{P}_{\mathrm{app}, \mathrm{s}-\mathrm{m}}$, $\mathrm{P}_{\mathrm{app}, \mathrm{m}-\mathrm{s}}$ and ER of LY in control rats were in line with

Table 3 mRNA expression of Mdr1a, Mrp2 and Bcrp in the small intestine with and without RFP

\begin{tabular}{llll}
\hline & & \multicolumn{2}{l}{ mRNA expression level (copy/ng RNA) } \\
\cline { 3 - 4 } & & Control & with RFP \\
\hline Mdr1a & Upper & $11,800 \pm 6900$ & $14,300 \pm 8300$ \\
& Middle & $22,600 \pm 5400$ & $33,600 \pm 11700^{*}$ \\
& Lower & $18,900 \pm 7200$ & $27,200 \pm 9300$ \\
Mrp2 & Upper & $396 \pm 164$ & $633 \pm 160^{*}$ \\
& Middle & $683 \pm 231$ & $1250 \pm 542^{*}$ \\
& Lower & $299 \pm 90$ & $425 \pm 131$ \\
& Upper & $3880 \pm 1460$ & $3650 \pm 921$ \\
& Middle & $2620 \pm 252$ & $2860 \pm 526$ \\
& Lower & $1250 \pm 228$ & $1170 \pm 430$ \\
\hline
\end{tabular}

Values are mean \pm SD of five rats. ${ }^{*} p<0.05$

Mdr1a multidrug resistance protein 1a, Mrp2 multidrug resistance-associated protein 2, Bcrp breast cancer resistance protein 
Table 4 Apparent permeability coefficient of Rho123 and inulin across the middle intestinal tissues of control rats

\begin{tabular}{|c|c|c|c|}
\hline & \multicolumn{3}{|c|}{$P_{\text {app }}\left(\times 10^{-6} \mathrm{~cm} / \mathrm{s}\right)$} \\
\hline & $\overline{m-s}$ & $s-m$ & ER \\
\hline Rho123 & $2.14 \pm 1.21$ & $4.11 \pm 2.85$ & 1.92 \\
\hline inulin & $1.40 \pm 1.27$ & $1.08 \pm 0.86$ & 0.771 \\
\hline
\end{tabular}

Values are mean $\pm S D$ of three rats

$m-s$ mucosal to serosal, $s-m$ serosal to mucosal, ER efflux ratio, $P_{a p p}$ apparent permeability coefficient, Rho123 rhodamine 123

those reported by Lin et al. [17]. The value of $\mathrm{P}_{\mathrm{app}}$ s-m of Rho123 $\left(4.11 \pm 2.85 \times 10^{-6} \mathrm{~cm} / \mathrm{s}\right)$ was higher than $\mathrm{P}_{\mathrm{app}}$, m-s $\left(2.14 \pm 1.21 \times 10^{-6} \mathrm{~cm} / \mathrm{s}\right)$. The ER of 1.92 confirmed active efflux transport of Rho123 in intestinal epithelial cells. These data suggest that the Ussing chamber system used here was suitable to evaluate drug permeability, especially focusing on P-gp.

Figure 2 and Table 5 show the time-course of the LZD permeation and the permeability of LZD across the upper, middle and lower intestinal tissues in RFP-pretreated and control rats. In control rats, there was no difference in the $\mathrm{P}_{\text {app }}$ values of LZD between the $\mathrm{m}$-s and $\mathrm{s}-\mathrm{m}$ directions in the upper, middle and lower intestine, and the values of ER of LZD showed no difference among all the intestinal regions, regardless of the site-specific expression of Mdr1a and Mrp2 mRNAs. RFP pretreatment did not increase the secretory transport of LZD at any site of the intestine, and also had no effect on the absorptive transport of LZD. The values of ER of LZD at each site of intestine showed no difference from those in control rats. The values of $\mathrm{P}_{\text {app,s-m}}, \mathrm{P}_{\mathrm{app}, \mathrm{m}-\mathrm{s}}$ and ER of LY also showed no significant differences between control and RFP-pretreated rats.

Table 5 Effect of RFP pretreatment on the apparent permeability coefficient of LZD across the intestinal tissues

\begin{tabular}{|c|c|c|c|c|c|}
\hline & & & $\mathrm{P}_{\mathrm{app}}\left(\times 10^{-6}\right.$ & & \\
\hline & & & m-s & $s-m$ & ER \\
\hline Upper & Control & LZD & $12.5 \pm 5.6$ & $11.6 \pm 5.2$ & 0.927 \\
\hline & & LY & $8.93 \pm 4.47$ & $8.41 \pm 4.14$ & 0.942 \\
\hline & with RFP & LZD & $13.6 \pm 5.5$ & $12.1 \pm 4.3$ & 0.891 \\
\hline & & LY & $9.09 \pm 4.49$ & $8.59 \pm 3.24$ & 0.944 \\
\hline Middle & Control & LZD & $9.19 \pm 2.27$ & $9.44 \pm 3.72$ & 1.03 \\
\hline & & LY & $6.60 \pm 2.90$ & $7.06 \pm 3.14$ & 1.07 \\
\hline & with RFP & LZD & $11.4 \pm 3.4$ & $10.2 \pm 2.9$ & 0.898 \\
\hline & & LY & $7.32 \pm 2.84$ & $7.12 \pm 2.65$ & 0.973 \\
\hline Lower & Control & LZD & $13.2 \pm 3.0$ & $10.3 \pm 4.5$ & 0.782 \\
\hline & & LY & $8.84 \pm 2.72$ & $6.88 \pm 3.77$ & 0.778 \\
\hline & with RFP & LZD & $14.3 \pm 4.0$ & $12.0 \pm 4.2$ & 0.842 \\
\hline & & LY & $8.85 \pm 3.04$ & $8.44 \pm 3.89$ & 0.953 \\
\hline
\end{tabular}

Values are mean \pm SD of five to six rats

$m$-s mucosal to serosal, $s-m$ serosal to mucosal, ER efflux ratio, $P_{a p p}$ apparent permeability coefficient, $L Y$ Lucifer yellow

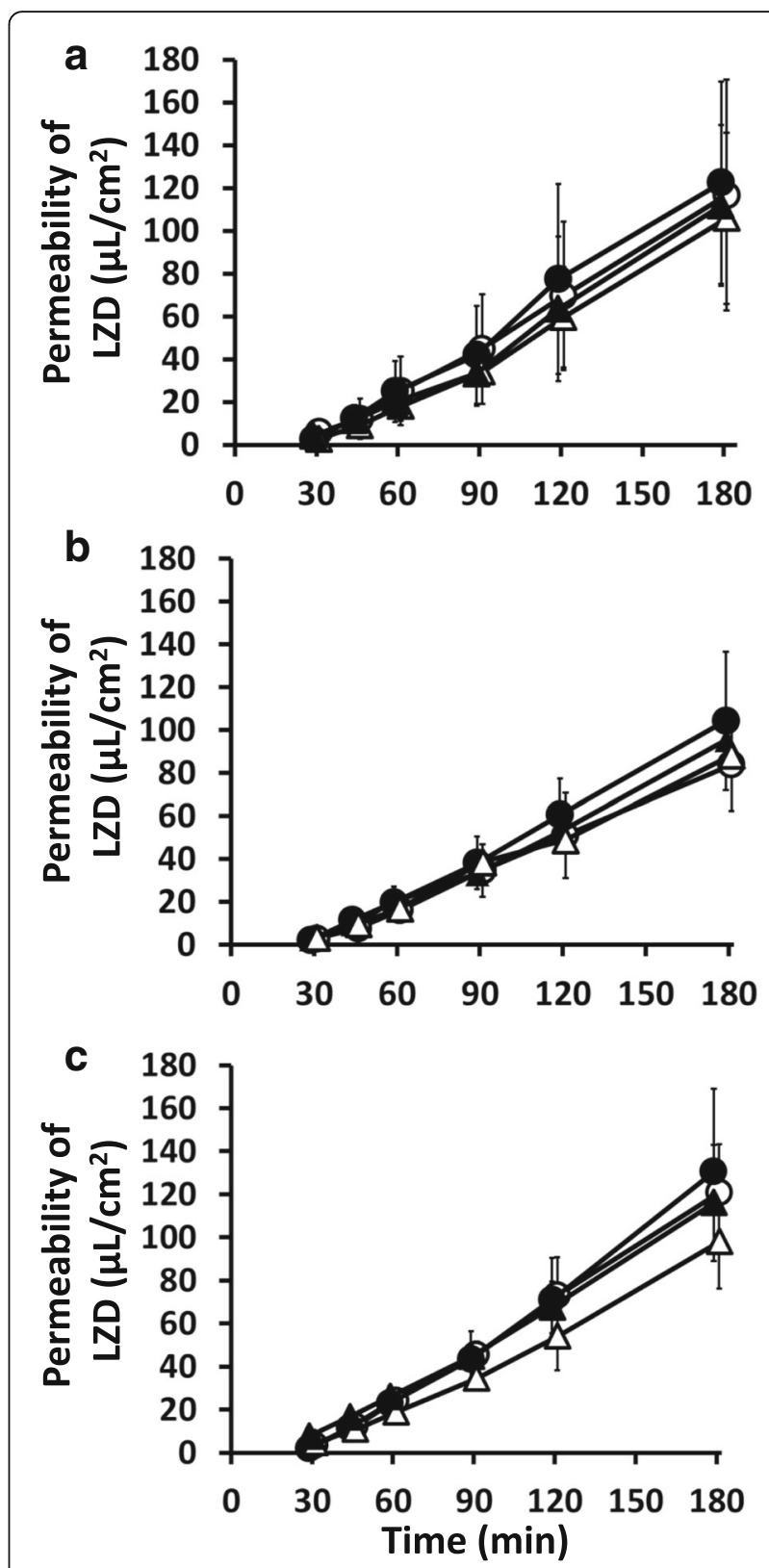

Fig. 2 Time course of linezolid permeation with and without RFP in an Ussing chamber experiment. Time course of the mucosal-toserosal transport (circle) and the serosal-to-mucosal transport (triangle) of linezolid across the rat (a) upper, (b) middle and (c) lower intestinal tissues with (closed) and without (open) RFP pretreatment $(10 \mathrm{mg} / \mathrm{kg})$ for four days. Values are expressed as the mean \pm SD $(n=5-6)$

\section{Discussion}

LZD plus RFP is a salvage therapy for multidrug-resistant tuberculosis and refractory bone and joint infections due to MRSA, because RFP is effective against bacteria producing a biofilm, while LZD shows good penetration into tissues and no cross-resistance to LZD has been found in strains resistant to other antibiotics [22-24]. Therefore, 
the use of LZD/RFP therapy has been increasing in recent years. However, there have been a few reports indicating that RFP decreases LZD exposure. This is important, because subtherapeutic levels of LZD present a risk of therapeutic failure and emergence of LZD-resistant strains.

The present clinical study is the first prospective demonstration of DDI between LZD and RFP in Japanese patients. The results of this prospective, open-label, uncontrolled study showed that RFP reduced the dose-normalized trough concentration of orally administered LZD by an average of $65 \%$. This finding is consistent with previous reports. Gandelman et al. found that the $\mathrm{C}_{\max }$ and AUC values for LZD were reduced by $21 \%$ and $32 \%$ in healthy subjects when LZD was administered orally after 8 days of pretreatment with RFP [12]. Pea et al. reported that the $\mathrm{C}_{\min }$ and AUC values for LZD were decreased by $63 \%$ and $42 \%$ when LZD was administered orally with RFP to patients [13]. We also encountered one patient who was excluded from this clinical study because RFP had been added after the initiation of LZD therapy. His C/D ratio of LZD decreased by about $60 \%$ after addition of RFP to LZD therapy, in agreement with a case report by Hoyo et al. [25]. It is important to note that the effect of adding RFP to LZD on the clinical outcome has not been well documented, and trough concentrations of LZD during LZD/ RFP therapy have not generally been monitored. However, our results suggest that the decrease of LZD exposure caused by RFP is too large to be disregarded. The DDI between LZD and RFP could contribute to the wide inter-individual variability in LZD exposure. Overall, currently available findings indicate that clinicians should routinely monitor LZD concentrations in patients receiving the combination therapy.

In our animal study, multiple doses of RFP significantly decreased the AUC, $C_{\max }$ and F of LZD when LZD was orally administered. In contrast, the pharmacokinetics of intravenously administered LZD showed no change in RFP-pretreated rats. These results of the animal experiments support the idea that LZD concentration is decreased only in the case of oral, but not intravenous, administration of LZD in patients receiving the combination therapy. These results suggested that RFP pretreatment might reduce the permeability of LZD. On the other hand, there are some reports that RFP decreased the trough concentration of LZD in patients even in the case of intravenous LZD administration $[26,27]$. The reasons for these apparently conflicting results are unclear, though possible explanations include species differences and differences of clinical conditions, e.g. CRP, because the inflammatory reaction could decrease the expression of some nuclear receptors which in turn control the expression of metabolizing enzymes and transporters [28].
Several mechanisms can be considered to explain the DDI, because RFP induces the expression of CYP3A4 and UDP-glucuronosyl-transferases in liver and intestine, and P-gp and MRP2 in intestine, while it inhibits organic anion transporting polypeptides in liver [29-38]. Multiple doses of RFP decreased exposure to digoxin and nifedipine (substrates of P-gp and CYP3A4/5, respectively) after oral administration of these drugs $[36,38]$. On the other hand, the effects were less pronounced after intravenous administration, as was seen in our experiment.

Because preadministration of RFP in rats had no effect on the clearance of LZD administered intravenously, and rat homologues cyp3a1/2 are not induced by RFP [39], we considered that a change of LZD permeability in the intestine could be involved in the reduction of LZD concentration in the case of oral administration. Therefore, we investigated the influence of RFP on mRNA expression of efflux transporters, and we also examined its effect on the intestinal permeability of LZD by means of an Ussing chamber experiment. However, multiple doses of RFP had no effect on the intestinal permeability of LZD, and no site-specificity in the small-intestinal absorption of LZD was found in the Ussing chamber experiment, even though intestinal Mdr1a and Mrp2 are expressed and induced site-specifically. These findings suggest that P-gp and MRP2 in the intestine make little contribution to the pharmacokinetics of LZD. Thus, the decrease of bioavailability of LZD after multiple doses of RFP appears not to be due to a decrease of intestinal permeability. The complicated DDIs with RFP can lead to apparently paradoxical observations in evaluation of the pharmacokinetics of co-administered drugs. Multiple doses of RFP had no effect on the small-intestinal absorption of LZD in the Ussing chamber experiment, even though Mdrla and Mrp2 are expressed in the intestine. In general, oral bioavailability is calculated as the product of absorption rate, intestinal availability, and liver availability. Our results indicated that RFP had no effect on the absorption rate or intestinal availability of LZD, suggesting that a first-pass effect in the liver may be the major contributor to the DDI between LZD and RFP.

Our study has some limitations. First, although the present study is the first prospective demonstration of DDI between LZD and RFP in Japanese patients, the small sample size in the clinical study limited the power of the statistical analysis. Further study with a larger number of cases will be needed to confirm our findings. Second, our results did not completely exclude the possibility that P-gp might be involved in the intestinal permeability of LZD, because we did not examine the effect of a P-gp inhibitor on the intestinal permeability. Third, it is not known whether coadministered RFP alters the metabolism of LZD, as the urinary excretion of LZD and its metabolites was not evaluated. 


\section{Conclusions}

Multiple doses of RFP decreased the AUC, $\mathrm{C}_{\max }$ and $\mathrm{F}$ of orally administered LZD in the case of combined treatment, but had no effect on LZD after intravenous administration in rats. However, RFP did not affect the intestinal absorption of LZD. Further work will be needed to establish the mechanism of the DDI between RFP and LZD.

\begin{abstract}
Abbreviations
AUC: Area under the concentration-time curve; Bcrp: Breast cancer resistance protein; C/D ratio: Dose-normalized trough concentration; $\mathrm{CL}_{\text {tot: }}$ :Total clearance; $C_{\max }$ : Maximum concentration; $C_{\text {min }}$ : Trough concentration; CRP: Creactive protein; CYP: Cytochrome P450; DDI: Drug-drug interaction; eGFR: Estimated glomerular filtration rate; ER: Efflux ratio; F: Bioavailability; Hb: Hemoglobin; HPLC: High performance liquid chromatography; $\mathrm{k}_{\mathrm{e}}$ : Elimination rate constant; LC/MS: Liquid chromatography-mass spectrometry; LY: Lucifer yellow; LZD: Linezolid; Mdr1a: Multidrug resistance protein 1a; Mrp2: Multidrug resistance-associated protein 2; MRSA: Methicillinresistant Staphylococcus aureus; $P_{a p p}$ : Apparent permeability coefficient; Pgp: P-glycoprotein; RFP: Rifampicin; Rho123: Rhodamine 123; $t_{1 / 2}$ : Half-life; TDM: Therapeutic drug monitoring; $V_{d}$ : Volume of distribution
\end{abstract}

\section{Acknowledgements}

This work was supported by the Japan Society for the Promotion of Science KAKENHI Grant Number 23590173 and 24926002

\section{Funding}

There are no funding sources for this report. This work was supported in part by the Japan Society for the Promotion of Science KAKENHI Grant Number 23590173 and 24926002

\section{Availability of data and materials}

The dataset supporting the conclusions of this article is included within the article.

\section{Authors' contributions \\ $\mathrm{SH}$ participated in the design of the study, performed the clinical portion of the study and wrote the manuscript. $\mathrm{KH}$ participated in the design of the study and carried out the LC/MS analysis and real-time PCR analysis. KF participated in the design of the study and carried out the LC/MS analysis and Ussing chamber analysis. YM participated in the design of the study and carried out the LC/MS analysis. KI, KM, YUS, SK, HT, YK, MO and TT participated in the study. TS analyzed the data and helped to draft the manuscript. YoS participated in the study and coordination and helped to draft the manuscript. All authors have read and approved the final manuscript.}

\section{Ethics approval and consent to participate}

Protocol of this study was approved by the Ethics Committee of Kanazawa University (UMIN000004322).

\section{Consent for publication}

Not applicable.

\section{Competing interests}

The authors declare that they have no competing interests.

\section{Publisher's Note}

Springer Nature remains neutral with regard to jurisdictional claims in published maps and institutional affiliations.

\section{Author details}

'Department of Hospital Pharmacy, University Hospital, Kanazawa University, 13-1, Takara-machi, Kanazawa, Ishikawa 920-8641, Japan. ²Department of Medicinal Informatics, Graduate School of Medical Sciences, Kanazawa University, 13-1, Takara-machi, Kanazawa, Ishikawa 920-8641, Japan. ${ }^{3}$ Faculty of Pharmacy, Institute of Medical, Pharmaceutical and Health Science, Kanazawa University, Kakuma-machi, Kanazawa, Ishikawa 920-1192, Japan.
${ }^{4}$ Department of Orthopaedic Surgery, Graduate School of Medical Sciences, Kanazawa University, 13-1 Takara-machi, Kanazawa, Ishikawa 920-8641, Japan. ${ }^{5}$ Intensive Care Unit, University Hospital, Kanazawa University, 13-1

Takara-machi, Kanazawa, Ishikawa 920-8641, Japan.

Received: 27 June 2018 Accepted: 23 October 2018

Published online: 12 November 2018

\section{References}

1. Corti G, Cinelli R, Paradisi F. Clinical and microbiologic efficacy and safety profile of linezolid, a new oxazolidinone antibiotic. Int J Antimicrob Agents. 2000;16:527-30.

2. Welshman IR, Sisson TA, Jungbluth GL, Stalker DJ, Hopkins NK. Linezolid absolute bioavailability and the effect of food on oral bioavailability. Biopharm Drug Dispos. 2001;22:91-7.

3. Wynalda MA, Hauer MJ, Wienkers LC. Oxidation of the novel oxazolidinone antibiotic linezolid in human liver microsomes. Drug Metab Dispos. 2000;28: 1014-7

4. Slatter JG, Stalker DJ, Feenstra KL, Welshman IR, Bruss JB, Sams JP, Johnson MG, Sanders PE, Hauer MJ, Fagerness PE, Stryd RP, Peng GW, Shobe EM. Pharmacokinetics, metabolism, and excretion of linezolid following an oral dose of $\left[{ }^{14} \mathrm{C}\right]$ linezolid to healthy human subjects. Drug Metab Dispos. 2001; 29:1136-45.

5. Tsuji Y, Hiraki Y, Matsumoto K, Mizoguchi A, Kobayashi T, Sadoh S, Morita K, Kamimura H, Karube $Y$. Thrombocytopenia and anemia caused by a persistent high linezolid concentration in patients with renal dysfunction. J Infect Chemother. 2011;17:70-5.

6. Nukui Y, Hatakeyama S, Okamoto K, Yamamoto T, Hisaka A, Suzuki H, Yata $\mathrm{N}$, Yotsuyanagi H, Moriya K. High plasma linezolid concentration and impaired renal function affect development of linezolid-induced thrombocytopenia. J Antimicrob Chemother. 2013;68:2128-33.

7. Cattaneo D, Orlando G, Cozzi V, Cordier L, Baldelli S, Merli S, Fucile S, Gulisano C, Rizzardini G, Clementi E. Linezolid plasma concentrations and occurrence of drug-related haematological toxicity in patients with grampositive infections. Int J Antimicrob Agents. 2013;41:586-9.

8. Matsumoto K, Shigemi A, Takeshita A, Watanabe E, Yokoyama Y, Ikawa K, Morikawa N, Takeda Y. Analysis of thrombocytopenic effects and population pharmacokinetics of linezolid: a dosage strategy according to the trough concentration target and renal function in adult patients. Int J Antimicrob Agents. 2014;44:242-7

9. Pea F, Furlanut $M$, Cojutti $P$, Cristini F, Zamparini E, Franceschi L, Viale P. Therapeutic drug monitoring of linezolid: a retrospective monocentric analysis. Antimicrob Agents Chemother. 2010;54:4605-10.

10. Pea F, Scudeller L, Lugano M, Baccarani U, Pavan F, Tavio M, Furlanut M Rocca GD, Bresadola F, Viale P. Hyperlactacidemia potentially due to linezolid overexposure in a liver transplant recipient. Clin Infect Dis. 2006;42: 434-5.

11. Bolhuis MS, van Altena $R$, van Soolingen $D$, de Lange WC, Uges DR, van der Werf TS, Kosterink JG, Alffenaar JW. Clarithromycin increases linezolid exposure in multidrug-resistant tuberculosis patients. Eur Respir J. 2013;42: 1614-21.

12. Gandelman K, Zhu T, Fahmi OA, Glue P, Lian K, Obach RS, Damle B. Unexpected effect of rifampin on the pharmacokinetics of linezolid: in silico and in vitro approaches to explain its mechanism. J Clin Pharmacol. 2011; 51:229-36.

13. Pea F, Viale P, Cojutti P, Del Pin B, Zamparini E, Furlanut M. Therapeutic drug monitoring may improve safety outcomes of long-term treatment with linezolid in adult patients. J Antimicrob Chemother. 2012;67:2034-42.

14. Soriano A, Ortega M, García S, Peñarroja G, Bové A, Marcos M, Martínez JC, Martínez JA, Mensa J. Comparative study of the effects of pyridoxine, rifampin, and renal function on hematological adverse events induced by linezolid. Antimicrob Agents Chemother. 2007;51:2559-63.

15. Legout L, Valette M, Dezeque H, Nguyen S, Lemaire X, Loïez C, Caillaux M, Beltrand E, Dubreuil L, Yazdanpanah Y, Migaud H, Senneville E. Tolerability of prolonged linezolid therapy in bone and joint infection: protective effect of rifampicin on the occurrence of anaemia? J Antimicrob Chemother. 2010; 65:2224-30.

16. Kageyama M, Fukushima K, Togawa T, Fujimoto K, Taki M, Nishimura A, Ito Y, Sugioka N, Shibata N, Takada K. Relationship between excretion clearance of rhodamine 123 and P-glycoprotein (Pgp) expression induced by representative Pgp inducers. Biol Pharm Bull. 2006;29:779-84. 
17. Lin Y, Shen Q, Katsumi H, Okada N, Fujita T, Jiang X, Yamamoto A. Effects of Labrasol and other pharmaceutical excipients on the intestinal transport and absorption of rhodamine123, a P-glycoprotein substrate, in rats. Biol Pharm Bull. 2007;30:1301-7.

18. Nishimura T, Kato Y, Amano N, Ono M, Kubo Y, Kimura Y, Fujita H, Tsuji A. Species difference in intestinal absorption mechanism of etoposide and digoxin between cynomolgus monkey and rat. Pharm Res. 2008;25:2467-76.

19. Cho HJ, Choi MK, Lin H, Kim JS, Chung SJ, Shim CK, Kim DD. Expression and functional activity of P-glycoprotein in passaged primary human nasal epithelial cell monolayers cultured by the air-liquid interface method for nasal drug transport study. J Pharm Pharmacol. 2011;63:385-91.

20. Dische Z, Borenfreund E. A new spectrophotometric method for the detection and determination of keto sugars and trioses. J Biol Chem. 1951; 192:583-7.

21. Naruhashi K, Sai Y, Tamai I, Suzuki N, Tsuji A. PepT1 mRNA expression is induced by starvation and its level correlates with absorptive transport of cefadroxil longitudinally in the rat intestine. Pharm Res. 2002;19:1417-23.

22. Agyeman AA, Ofori-Asenso R. Efficacy and safety profile of linezolid in the treatment of multidrug-resistant (MDR) and extensively drug-resistant (XDR) tuberculosis: a systematic review and meta-analysis. Ann Clin Microbiol Antimicrob. 2016; https://doi.org/10.1186/s12941-016-0156-y.

23. Tang HJ, Chen CC, Cheng KC, Wu KY, Lin YC, Zhang CC, Weng TC, Yu WL, Chiu YH, Toh HS, Chiang SR, Su BA, Ko WC, Chuang YC. In vitro efficacies and resistance profiles of rifampin-based combination regimens for biofilmembedded methicillin-resistant Staphylococcus aureus. Antimicrob Agents Chemother. 2013;57:5717-20.

24. Vergidis P, Rouse MS, Euba G, Karau MJ, Schmidt SM, Mandrekar JN, Steckelberg JM, Patel R. Treatment with linezolid or vancomycin in combination with rifampin is effective in an animal model of methicillinresistant Staphylococcus aureus foreign body osteomyelitis. Antimicrob Agents Chemother. 2011;55:1182-6.

25. Hoyo I, Martínez-Pastor J, Garcia-Ramiro S, Climent C, Brunet M, Cuesta M, Mensa J, Soriano A. Decreased serum linezolid concentrations in two patients receiving linezolid and rifampicin due to bone infections. Scand J Infect Dis. 2012;44:548-50.

26. Ashizawa N, Tsuji Y, Kawago K, Higashi Y, Tashiro M, Nogami M, Gejo R, Narukawa M, Kimura T, Yamamoto Y. Successful treatment of methicillinresistant Staphylococcus aureus osteomyelitis with combination therapy using linezolid and rifampicin under therapeutic drug monitoring. J Infect Chemother. 2016;22:331-4

27. Gebhart BC, Barker BC, Markewitz BA. Decreased serum linezolid levels in a critically ill patient receiving concomitant linezolid and rifampin. Pharmacotherapy. 2007;27:476-9.

28. Assenat E, Gerbal-Chaloin S, Larrey D, Saric J, Fabre JM, Maurel P, Vilarem MJ, Pascussi JM. Interleukin 1 beta inhibits CAR-induced expression of hepatic genes involved in drug and bilirubin clearance. Hepatology. 2004; 40:951-60.

29. Combalbert J, Fabre I, Fabre G, Dalet I, Derancourt J, Cano JP, Maurel P. Metabolism of cyclosporin A. IV. Purification and identification of the rifampicin-inducible human liver cytochrome P-450 (cyclosporin A oxidase) as a product of P450IIIA gene subfamily. Drug Metab Dispos. 1989;17:197-207.

30. Kolars JC, Schmiedlin-Ren P, Schuetz JD, Fang C, Watkins PB. Identification of rifampin-inducible P450IIIA4 (CYP3A4) in human small bowel enterocytes. J Clin Invest. 1992;90:1871-8

31. Reinach B, de Sousa G, Dostert P, Ings R, Gugenheim J, Rahmani R. Comparative effects of rifabutin and rifampicin on cytochromes P450 and UDP-glucuronosyl-transferases expression in fresh and cryopreserved human hepatocytes. Chem Biol Interact. 1999;121:37-48.

32. Schuetz EG, Beck WT, Schuetz JD. Modulators and substrates of Pglycoprotein and cytochrome P4503A coordinately up-regulate these proteins in human colon carcinoma cells. Mol Pharmacol. 1996;49:311-8.

33. Fromm MF, Kauffmann HM, Fritz P, Burk O, Kroemer HK, Warzok RW Eichelbaum M, Siegmund W, Schrenk D. The effect of rifampin treatment on intestinal expression of human MRP transporters. Am J Pathol. 2000;157: $1575-80$.

34. Oswald S, Haenisch S, Fricke C, Sudhop T, Remmler C, Giessmann T, Jedlitschky G, Adam U, Dazert E, Warzok R, Wacke W, Cascorbi I, Kroemer HK, Weitschies W, von Bergmann K, Siegmund W. Intestinal expression of Pglycoprotein $(A B C B 1)$, multidrug resistance associated protein 2 ( $A B C C 2$ ) and uridine diphosphate-glucuronosyltransferase $1 \mathrm{~A} 1$ predicts the disposition and modulates the effects of the cholesterol absorption inhibitor ezetimibe in humans. Clin Pharmacol Ther. 2006;79:206-17.

35. Shitara Y. Clinical importance of OATP1B1 and OATP1B3 in drug-drug interactions. Drug Metab Pharmacokinet. 2011:26:220-7.

36. Greiner B, Eichelbaum M, Fritz P, Kreichgauer HP, von Richter O, Zundler J, Kroemer HK. The role of intestinal P-glycoprotein in the interaction of digoxin and rifampin. J Clin Invest. 1999;104:147-53.

37. Gallicano KD, Sahai J, Shukla VK, Seguin I, Pakuts A, Kwok D, Foster BC Cameron DW. Induction of zidovudine glucuronidation and amination pathways by rifampicin in HIV-infected patients. Br J Clin Pharmacol. 1999; 48:168-79.

38. Holtbecker N, Fromm MF, Kroemer HK, Ohnhaus EE, Heidemann H. The nifedipine-rifampin interaction. Evidence for induction of gut wall metabolism. Drug Metab Dispos. 1996;24:1121-3.

39. Jones SA, Moore LB, Shenk JL, Wisely GB, Hamilton GA, McKee DD, Tomkinson NC, LeCluyse EL, Lambert MH, Willson TM, Kliewer SA, Moore JT. The pregnane $X$ receptor: a promiscuous xenobiotic receptor that has diverged during evolution. Mol Endocrinol. 2000;14:27-39.
Ready to submit your research? Choose BMC and benefit from:

- fast, convenient online submission

- thorough peer review by experienced researchers in your field

- rapid publication on acceptance

- support for research data, including large and complex data types

- gold Open Access which fosters wider collaboration and increased citations

- maximum visibility for your research: over $100 \mathrm{M}$ website views per year

At BMC, research is always in progress.

Learn more biomedcentral.com/submissions 